\title{
Bir aile hekimliği birimine başvuran hipertansiyon tanılı bireylerin hastalıkla ilişkili bilgi düzeyi ve tutumları
}

\section{Behaviors and knowledge of hypertensive patients at a family medicine unit}

\author{
๑Dinçer Atila ${ }^{1}$, ๑Yasemin Kılıç Öztürk ${ }^{2}$, ๑Vatan Barışık ${ }^{3}$, ĐElif Okşan Çalıkoğlu ${ }^{4}$ \\ ${ }_{1}^{1} 1$ No’lu Aile Sağlığı Merkezi, Aile Hekimliği, İzmir, Türkiye \\ ${ }^{2}$ Sağlık Bilimleri Üniversitesi, Tepecik Eğitim ve Araştırma Hastanesi, Aile Hekimliği Kliniği, İzmir, Türkiye \\ ${ }^{3}$ Karşıya Özel Metropol Tıp Merkezi, İç Hastalıkları Bölümü, İzmir, Türkiye \\ ${ }^{4}$ Atatürk Üniversitesi Tip Fakültesi Halk Sağlığı Anabilim Dalı, Erzurum, Türkiye
}

Cite this article as/Bu makaleye atıf için: Atila D, Kılıç Öztürk Y, Barışık V, Çalıkoğlu EO. Bir aile hekimliği birimine başvuran hipertansiyon tanılı bireylerin hastalıkla ilişkili bilgi düzeyi ve tutumları. J Med Palliat Care 2021; 2(3): 66-70.

\section{Öz}

Giriş: Bu çalışmada, İzmir Menemen 1 No’lu Aile Sağlığı Merkezine başvuran hipertansif hastaların hastalıkla ilgili bilgi ve tutumlarının araştırılması amaçlanmıştır.

Gereç ve Yöntem: Tanımlayıcı-kesitsel tasarımdaki bu çalışma 24 Mart - 30 Ağustos 2021 tarihleri arasında Menemen 1 No’lu Aile Sağlığı Merkezi’nde yürütülmüştür. Hastaların sosyo-demografik verileri, kronik hastalık öykülerive hipertansiyon tanı ve tedavisiyle ilgili bilgi düzeyi ve tutumlarına yönelik sorular içeren anket formu yüzyüze görüşme tekniği ile uygulandı. Verilerin analizi SPSS 16.0 paket programıla yapıldı.

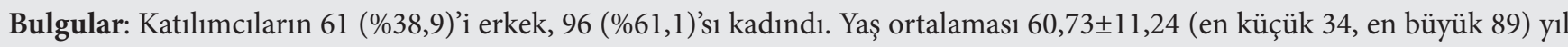
idi. Katılımcıların çoğunluğu $(\% 90,4)$ ilköğretim mezunuydu, 99 (\%63,1) kişide kronik hastalık öyküsü saptandı, 39 (\%24,8) kişi düzenli egzersiz yaptığını belirtti.

Sonuç: Araştırmada katılımcıların hipertansiyonla ilgili bilgi düzeylerinin yeterli olmadığı saptandı. Hastalar hipertansiyon konusunda bilgilendirilmeli, düzenli doktor kontrolü ve ilaç kullanımı konusunda yönlendirilmelidir. Topluma yönelik eğitim projeleri planlanmalıdır.

Anahtar Kelimeler: Koruyucu hekimlik, hipertansiyon, yaşam tarzı

\begin{abstract}
Introduction: In this study, it was aimed to examine the knowledge and behaviors of hypertensive patients who applied to Izmir Menemen Family Medicine Unit.

Material and Method: This descriptive cross-sectional study was conducted between the $24^{\text {th }}$ March and the $30^{\text {th }}$ of August 2021 Family Health Center Number 1, Menemen, İzmir. A questionnaire form including questions on socio-demographic data, histories of chronic disease and knowledge level and attitudes about the diagnosis and treatment of hypertension was applied using face-to-face interview technique. Frequency tests and Pearson's Chi-Square test was used to analyze the data.

Results: Of the participants, 61 (38.9\%) were men, and 96 (61.1\%) were women. The mean age was $60.73 \pm 11.24$ years. Most of the participants (90.4\%) were primary school graduates. A history of chronic disease was found in 99 (63.1\%) people, 39 (24.8\%) people stated that they exercise regularly.

Conclusion: In the study, it was determined that the knowledge level of the participants about hypertension was not sufficient. Patients should be informed about hypertension, andshould be guided about regular doctor control and drug use. Educational projects for the society should be planned.
\end{abstract}

Keywords: Preventive medicine, hypertension, life style 


\section{GíRiş}

Hipertansiyon (HT) büyük çapta önlenebilir ve kontrol altına alınabilir bir hastalık olmasına karşılık, tüm dünyada önemli düzeyde morbidite ve mortaliteye yol açmaktadır. Yüksek kan basıncı koroner kalp hastalığı, kalp yetmezliği, serebrovasküler hastalık, renal yetmezlik, periferik damar hastalığı, retinal damarlarda bozulma ve görme kaybına yol açabilir (1). Yapılan bir çalışmada 2000 yılı itibariyle dünyada erişkin nüfusun \%26,4'ünün HT’u olduğu ve bu oranın 2025 yılında \%29,2'ye çıkacağı öngörülmüștür. Bir diğer deyişle, halen 972 milyon insanın HT'u vardır ve 2025 yılında bu rakam 1,5 milyarı aşacaktır. Dolayısıyla HT günümüzde ve gelecekte önemli bir halk sağlığ sorunu olmaya devam edecektir. Prevelansı ülkeden ülkeye değişmekle birlikte, genel populasyonda yaklaşı \%30-45 oranında gözlenmekte ve bu oran yaşla birlikte artmaktadır (2-4). Hipertansiyon hastalı̆̆ıhakkında bilgi düzeyi arttıkça,buna paralel olarak hipertansiyon tanısı, tedavisi ve kontrolaltına alma oranları da artacaktır. İnsanların hipertansiyonhastalığı hakkında bilgi düzeylerindeki eksikliklerin saptanması, eksiklikleri gidermeye yardımcı olacaktır $(4,5)$.

Bu çalışmada, Menemen 1 No'lu Aile Sağlığı Merkezi’ne başvuran hipertansiyon tanısı almış kişilerin hipertansiyon hastalığı hakkındaki bilgi düzeylerinin ve bu hastalık ile mücadele etmede davranışlarının araştırılması amaçlanmıştır.

\section{GEREÇ VE YÖNTEM}

\section{Araştırma Tasarımı}

Tanımlayıcı-kesitsel tipte planlanan bu araştırma S.B.Ü. İzmir Tepecik Eğitim ve Araştırma Hastanesi'nden etik kurul onayı (Tarih: 12.10.2020, Karar No: 2020/12-30) ve İzmir Halk Sağlığg Kurumu'ndan (Tarih: 24.03.2021, Karar No: E-36026262-702.99) izin alındıktan sonra 24 Mart-30 Ağustos 2021 tarihleri arasında İzmir, Menemen 1 No'lu Aile Sağlı̆̆ı Merkezi’nde yapıldı. Tüm katılımcılara sözlü bilgi verilerek yazılı onamları alındı. Hastaların sosyo-demografik verileri, kronik hastalık öyküleri ve hipertansiyon tanı ve tedavisiyle ilgili bilgi düzeyi ve tutumlarını araştırmaya yönelik sorular içeren anket formu her bir hasta için yaklaşık 10 dakika süre ayrılarak yüz yüze görüşme tekniği ile uyguland. Verilerin analizinde tanımlayıcı istatistiksel analizler ve Pearson Ki-Kare testi ve Fisher's exact testi kullanıldı.

\section{Ortam}

Çalışma İzmir, Menemen 1 No'lu Aile Sağllğı Merkezi’nde yapıldı. Aile sağlığ 1 merkezi 9 aile hekimliği biriminden oluşmaktadır. Aile hekimliği birimimizde 3910 kişi kayıtlı olup, günde ortalama 60 kişiye sağlık hizmeti verilmektedir. Tanı ve tedavi hizmetlerinin yanısıra sağlık eğitimi, bağışıklama, üreme sağlı̆̆ı, gebe, bebek ve çocuk izlemleri gibi temel koruyucu sağlık hizmetleri de sürdürülmektedir.

\section{Katılımcılar ve Örneklem}

Araştırmanın evreni birimde kayıtlı hipertansiyon tanılı 356 kişiden oluşmaktadır. Araştırmada örneklem hesabı yapılmaksızın 3 aylı zaman diliminde birimimize başvuran ve dahil edilme kriterlerine uyan tüm bireyler araştırma kapsamında değerlendirildi. Araştırma 24 Mart-30 Ağustos 2021 tarihleri arasında 157 kişi ile tamamlandi.

\section{Değişkenler}

Araştırmacılar tarafindan oluşturulan anket formu hakkında katılımcılarabilgilendirme yapılarak sözlü ve yazılı onamları alındıktan sonra anket formu araştırmacı tarafından yüz yüze görüşme tekniği ile uygulandı. Anket formu; hastaların sosyo-demografik verileri, kronik hastalık öyküleri ve hipertansiyon tanı ve tedavisiyle ilgili bilgi düzeyi ve tutumlarını araştırmaya yönelik soruları içeren 18 sorudan oluşmaktaydı. Araştırma değişkenleri, yaş (yıl), cinsiyet (erkek/kadın), medeni durum (evli/bekâr), eğitim durumu (orta öğretim, lise ve üniversite), sigara içme durumu, kronik hastalık öyküsü (diabetes mellitus, aterosklerotik kalp hastalığ 1 , kronik akciğer hastalığı, kronik böbrek hastalığ 1 , kronik karaciğer hastalığı), yüksek tansiyon değerinin bilinmesi, kullanılan tansiyon ilacının adının bilinmesi, tansiyon takibinin yapılması, tansiyon takibinin ne siklıkta yapıldığı, diyete uyulması, egzersiz yapılması, egzersiz yapılma sıklığıgibi verilerden oluşmaktaydı.

\section{Hata Önleme (Bias)}

Ankette, araştırma verilerinin doğru bir şekilde elde edildiğinden emin olmak için araştırma hakkında kısaca bilgi verilmiştir ve katılımcıların kimliklerinin hasta tanıtıcı formuna yazılmayacağı söylenmiştir. Biası önlemek için, aile hekimliği birimimize başvuran 18 yaş üzeri, çalışmaya katılmayı kabul eden tüm hipertansif hastalar araştırmaya katılmaya davet edildi. Bilgisayara girilen verilerin hata denetimi ve hata ayıklaması yapıldı.

\section{İstatistiksel Yöntemler}

Veriler SPSS 16.0 paket programıla analiz edilmiştir. Tanımlayıcı istatistikler olaraksayı, yüzde ortalama, standart sapma hesaplandi. Sonuçlar ortanca, birinci ve üçüncü çeyrek olarak sunuldu. Kategorik değişkenlerin karşılaştırılmasında ise Pearson ki-kare testi (gerektiğinde Fisher's exact test) yapıldı. İstatistiksel olarak anlamlılık düzeyip $<0,05$ kabul edildi.

\section{BULGULAR}

\section{Katılımcılar}

Verileri analiz edilen 157 kişinin yaş ortalaması $60,73 \pm 11,24$ (en küçük 34, en büyük 89) y1l idi. Çalışamaya katılanların çoğunluğu $(\% 61,1)$ kadın, evli $(\% 73,9)$ ve ortaöğretim $(\% 90,4)$ mezunuydu. Katılımciların sosyodemografik özellikleri Tablo 1'de sunuldu. 
Tablo 1. Katılımcıların sosyo-demografik özellileri

\begin{tabular}{|llcc|}
\hline \multirow{2}{*}{ Yaş } & & \multicolumn{2}{c|}{ Ort \pm SS } \\
\cline { 3 - 4 } & & \multicolumn{2}{c|}{$60,73 \pm 11,24$} \\
\hline \multirow{2}{*}{ Cinsiyet } & Kadı1 & 96 & $\%$ \\
& Erkek & 61 & 38,1 \\
& Ortaöğretim & 142 & 90,4 \\
Öğrenim & Lise & 11 & 7 \\
durumu & Üniversite & 4 & 2,5 \\
\hline
\end{tabular}

Katılımcıların 99 (\%63,1)'unda kronik hastalık öyküsü saptandı. Katılımciların $60 \quad(\% 38,2)$ 'inda diabetes mellitus, 43'ünde $(\% 27,4)$ aterosklerotik kalp hastalığı, 38 (\%24,2)'inde kronik akciğer hastalı̆̆ı, 4 (\%2,5)'ünde kronik böbrek hastalığı, $1(\% 0,6)$ 'inde kronik karaciğer hastalığ ${ }_{1}$ öyküsü saptandı. Kronik hastalık öyküsü olan 26 $(\% 26,3)$ kişinin kullandığı tansiyon ilacının adını bildiği, 73 $(\% 73,7)$ kişinin ise bilmediği saptandı. Tansiyon ilaçlarının adını bilen hastalar ile bilmeyen hastalar arasında kronik hastalık öyküsü açısından istatistiksel olarak anlamlı bir fark olmadığı saptandı. Kronik hastalıkları ile katılımcıların davranış özellikleri Tablo 2'de sunuldu.

Tablo 2. Kronik hastalıklar ile katılımcıların davranış özellikleri

\begin{tabular}{|lcccccccccc|}
\hline & & \multicolumn{2}{c}{$\begin{array}{c}\text { Tansiyon } \\
\text { takibinin } \\
\text { yapılması }\end{array}$} & \multicolumn{2}{c}{$\begin{array}{c}\text { Diyete } \\
\text { uyulması }\end{array}$} & \multicolumn{2}{c|}{$\begin{array}{c}\text { Egzersiz } \\
\text { yapılması }\end{array}$} & \multicolumn{2}{c|}{$\begin{array}{c}\text { Sigara } \\
\text { içilmesi }\end{array}$} \\
\cline { 2 - 11 } & & sayı & $\%$ & sayı & $\%$ & sayı & $\%$ & sayı & $\%$ \\
\hline $\begin{array}{l}\text { Kronik } \\
\text { hastalık } \\
\begin{array}{l}\text { öyküsü } \\
\text { olanlar }\end{array}\end{array}$ & Evet & 51 & 51,5 & 41 & 41,4 & 27 & 27,3 & 13 & 13,3 \\
\hline
\end{tabular}

Araştırmaya katılanların $22 \quad(\% 14,0)$ 'si sigara kullandıklarını belirtti. Katılımcıların $144 \quad(\% 91,7)$ 'üyüksek tansiyon değerini bilmediğini, $113(\% 72,0)$ kişi de kullandığı tansiyon ilacının adını bilmediğini belirtti. Erkeklerin 19 (\%31,1)'u ve kadinların 25 (\%26,0)'i kullandığ 1 tansiyon ilacının adını biliyordu, $82(\% 52,2)$ kişi, kan basıncı takibi yaptığını belirtirken, 17 (\%10,8) kişi günde bir kez, 46 (\%29,3) kişi haftada bir kez ve 19 $(\% 12,1)$ kişi de ayda bir kez kan basıncı takibi yaptığını belirtti. Katılımcıların $61(\% 38,9)$ 'i diyete uyduğunu,
$39(\% 24,8)$ kişi düzenli eegzersiz yaptığını belirtti; 28 $(\% 17,8)$ kişi günde bir kez, $11(\% 7,0)$ kişi haftada bir kez düzenli egzersiz yaptığını belirtti. Kronik hastalıklar ile tansiyon takibinin yapılması anlamlı bulunurken, diyete uyulması, egzersiz yapılması ve sigara içilmesi açısından istatistiksel olarak anlamlı bir fark saptanmadı. Katılımcıların sosyo-demografik özelliklerine göre hipertansiyon kontrolü ile ilgili davranışları Tablo 3 'te sunuldu.

Katılımcıların çoğunluğu orta öğretim mezunu olduklarından öğrenim durumuna göre karşılaştırmalar yapılmamıştır.

\section{TARTIŞMA}

\section{Anahtar Bulgular}

$\mathrm{Bu}$ araştırmada aile sağlığı merkezine müracaat eden kişilerin eğitim seviyelerinin ve hipertansiyon hakkında bilgi düzeylerinin düşük olduğu bulundu. Hastaların hipertansiyon ile mücadele etmede yeterli koruyucu önlemleri almadıkları saptandı. Cinsiyetler arasında yüksek kan basıncı değerinin bilinmesi, düzenli kan basıncı takibinin yapılması ve diyete uyulması açısından istatistiksel olarak anlamlı bir fark saptanmadı.

\section{Kisitlilıklar}

Bu çalışmanın bazı kısıtllıkları şu şekilde belirtilebilir: İlk olarak bireylerin kendi ifadelerinin esas alınarak doğru kabul edildiği, gözlemsel boyutu bulunmayan veri toplama yöntemi, anket çalışmalarının sınırlarını teşkil etmektedir. İkinci olarak veriler aile sağlığ 1 merkezine müracaat eden kişilerden ve tek birime başvuran bireylerle yürütüldüğünden çoğunlukla aynı sosyo-ekonomik bölgede ikamet etmelerinden dolayı toplumun diğer kesimlerine genellenemez. Ayrica, hipertansiyon bilgi düzeyi, tutum ve davranışları belirlemeye yönelik geçerli ve güvenilir bir ölçek bulunmadığından dolayı durum değerlendirmesi yapmaya yönelik sorularla bilgi düzeyi skorlaması yapılamamıştır. Düzenli egzersiz, diyete uyum gibi başlıkların kişilerin kendi anlayışına göre öznel olarak değerlendirilmesi bir diğer kısıtlılıktır.

\begin{tabular}{|llcccccccccc} 
Tablo 3. Katılımcıların sosyo-demografik özelliklerine göre hipertansiyon kontrolü ile ilgili davranışları \\
\hline
\end{tabular}

Katılımcıların çoğunluğu orta öğretim mezunu olduklarından öğrenim durumuna göre karşılaştırmalar yapılmamıștır. 


\section{Yorum}

Jian ve ark. (5) Kuzey Carolina'da 24 aile hekimliği merkezinde yaptıkları çalışmada; hipertansiyonun kadınlarda daha yüksek oranda olduğu ve araştırma grubu içerisinde kadınların oranının daha fazla olduğu bulunmuştur. Çalışmamızda benzer şekilde kadınların çalışmaya katılım oranı yüksek $(\% 61,19)$ bulunmuştur. Bunun nedeni kadınların sağlık hizmetlerinden daha fazla yaralanıyor olmaları ve erkeklerin gündüz saatlerinde çalışmaları araştırmaya katılım oranlarını etkilemiş olabilir (6).

İzmir'de bir sağlık ocağına başvuran poliklinik hastalarının hipertansiyon hakkındaki bilgi, tutum ve görüşlerinin değerlendirildiği bir çalışmada katılımcıların \%9,8’i üniversite mezunu olduklarını belirtmiştir (7). Çalışmamızda ise bu oran \%2,5 olarak bulunmuştur ve eğitim seviyesinin düşük olmasının nedeni birimimize bağlı bölgenin çok fazla göç almasına atfedilebilir.

Arslantaş ve ark. (8) Kayseri’de 4 farklı aile sağlı̆̆ merkezinde yaptıkları araştırmada; çalışmaya katılanların \%59,2'si hipertansiyon dişında başka bir kronik hastalığ daha olduğunu belirtmiştir. Çalışmamızda kronik hastalık öyküsü daha yüksek olarak saptanırken $(\% 63,1)$, en sik diyabet $(\% 38,2)$, en az ise kronik karaciğer hastalığ $(\% 0,6)$ saptanmıştır. Aypak ve ark. (9) yaptıkları çalışmada hipertansiyon hastalığı olan kişilerde diyabet oranını \%13,5 olarak bulmuşlardır. Singapur'da yapılan kesitsel bir çalışmada; katılımcılarda diyabet oranını 5,9 olarak bulunmuş ve hipertansiyonla birlikte kronik hastalığa sahip olan kişilerin yaşam kalitesinin bozulduğu belirtilmiştir (10). Viera Aj ve ark. (5) yaptıkları çalışmada hipertansiyon değerinin bilinmesi oranı \%84,0 olarak saptanmıştır. Çalışmamızda ise hipertansiyon değerinin bilinmesi oranı literatürün aksine düşük bulunmuştur $(\% 8,3)$. Bu sonucun çalışmanın yürütüldüğü örneklem grubunun eğitim ve sosyo-ekonomik düzey ile ilgili olduğu düşünülmektedir (7). Amerika Birleşik Devletleri (ABD)'nde yapılan başka bir araştırmada ise çalışmaya katılan kişilerin üçte ikisinin hipertansiyon değerini doğru bildikleri ve eğitim seviyesinin yüksek olanlarda bu oranın anlamlı olarak yüksek olduğu saptanmıştır (11). Çalışmamızda hipertansiyon değerinin bilinmesi \%8,3 saptandı. Bölgemize kayıtlı kişilerin çoğunluğunun $(\% 90,4)$ orta öğretim mezunu olmalarından dolayı eğitim seviyesi ile hipertansiyon değerinin bilinmesi analizi yapılamamıştır. Ülkemizde yapılan bir çalışmada ise hastaların kullandığı ilacın adının bilinmesi oranı \%25,3 bulunurken (9), çalışmamızda oranın benzer şekilde \%28,0 olduğu saptanmıştır. Aynı çalışmada kadınların erkek hastalara göre daha fazla oranda kullandığı ilacının adını bildiği saptanmış. Çalışmamızda literatürün aksine erkek hastaların \%31,1'inin, kadın hastaların \%26,0'ının kullandığı ilacın adını bildiği, erkek ve kadın grupları arasında anlamlı fark olmadığı saptandı. Kan basıncı regülasyonunda rol aldığı düşünülen başlıca yaşam tarzı değişiklikleri, fazla kilolu ve şişman kişilerde kilo verme $(12,13)$, potasyum ve kalsiyumdan zengin diyet uygulanması $(14,15)$, diyetle alınan sodyum miktarının azaltılması $(14,16)$, düzenli fiziksel aktivite ve egzersizdir $(17,18)$. Kayseri'de 4 farklı aile sağlığı merkezinde yapılan çalışmada; erkek hastaların \%47,5'i, kadın hastaların ise \%36,0'1 düzenli fiziksel aktivitede bulunduğunu belirtmiş ve gruplar arasındaki fark anlamlı bulunmuştur (8). Çalışmamızda erkeklerin \%41,0’ının, kadınların \%14,6'sının düzenli egzersiz yaptı̆̆ ve gruplar arasında anlamlı fark olmadığı saptanmıştır. Düzenli fiziksel aktivitenin hipertansiyonlu hastalarda mortaliteyi azalttı̆̆ı gösterilmiştir (19). ABD'de yapılan bir çalışmada antihipetansif tedaviye yardımcı olarak kilo verilmesi, stresin azaltılması ve tuz kısıtlaması olarak bildirilmiştir (11). Aypak ve ark. (9) yaptığı çalışmada düzenli diyete uyulması \%13,6 (n=46) olarak saptanmış, erkek hastalarda düzenli diyet yapma oranı kadın hastalara göre daha yüksek saptanmıştır. Çalışmamızda literatürün aksine düzenli diyet yapılması \%38,9 olarak saptanmış olup, erkeklerin \%32,8'inin; kadınların \%42,7'sinin düzenli diyet yaptığı saptanmıştır. Cinsiyetler arasında anlamlı fark olmadığı saptanmıştır.Özer ve ark. yapmış oldukları çalışmada katılımcıların \%81,4'ünün düzenli tansiyon ölçümü yaptırmadıkları saptanmış. Çalışmamızda literatürün aksine katılımcıların \%47,8'i düzenli kan basıncı takibi yapmadığını belirtmiştir $(20,21)$. Sağlık Bakanlığg’nın hekimlere yönelik birinci basamak hipertansiyon eğitimi modülünde, 18 yaşından büyük tüm sağlıklı kişilerde kan basıncı ölçümü yılda en az bir kez ölçülmesi, erişkin hastalarda her klinik muayenede kan basıncının mutlaka ölçülmesi önerilmektedir. Ayrıca kan basıncı normal (sistolik < 130 / diyastolik <80 mmHg) olan hastaların 2 yılda bir kontrole çağrılması, kan basınc1 yüksek (sistolik 130-139 / diyastolik 80-89 mmHg) olan hastalara hayat tarzı değişikliği önerilmesi gerektiğini ve yıllık kontrole çağrılması vurgusu yapılmaktadır. Ürdün'de yapılanbir araştırma da ise yüksek hipertansiyon bilgi düzeylerinintedaviye ve yaşam tarzı değişikliklerine yüksek uyumla ilişkili olduğu görülmüştür (22). Bu çalışmayı destekler şekilde normal kan basıncı değerini bilenlerin \%84,6'sı düzenli olarak kan basincı takibi yapmaktaydı. Teke yapmış olduğu yüksek lisans tezinde hipertansiyon hastalı öyküsü olanların hipertansiyon hakkında bilgi düzeylerinin yüksek olduğunu saptamıştır. Çalışmamızda literatürün aksine kronik hastalık öyküsü olanların \%26,3'ünün kullandığı tansiyon ilacının adını bildiği saptandı.

\section{SONUÇ}

$\mathrm{Bu}$ araştırmada katılımcıların hipertansiyon ile ilgili bilgi düzeylerinin düşük olduğu, bu hastalıkla mücadelede kendi tutumlarının yetersiz olduğu ve 
yeterli koruyucu önlemler almadıkları saptanmıştır. Kişiye özel bireyselleştirilmiş danışmanlık hizmetleri ve yaşam tarzına yönelik davranışlarının objektif değerlendirilebilmesinin hasta otonomisi açısından önemli olduğu düşünülmektedir.

Sık görülen sağlık sorunlarının yönetilmesinde yetkin olması beklenen ve koruyucu sağlı uygulamalarına odaklı aile hekimlerinin hipertansiyon ve mücadelede daha etkin rol almaları gerekmektedir.

\section{ETIK BEYANLAR}

Etik Kurul Onayı: Çalışma için Sağlık Bilimleri Üniversitesi İzmir Tepecik Eğitim ve Araştırma Hastanesi'nden (Tarih: 12.10.2020, Karar No: 2020/1230) ve İzmir Halk Sağlığ 1 Kurumu'ndan (Tarih: 24.03.2021, Karar No: E-36026262-702.99) etik kurul onayı alınmıştır.

Aydınlatılmış Onam: Bu çalışmaya katılan hasta(lar) dan yazılı onam alınmıştır.

Hakem Değerlendirme Süreci: Harici çift kör hakem değerlendirmesi.

Çıkar Çatışması Durumu: Yazarlar bu çalışmada herhangi bir çıkara dayalı ilişki olmadı̆̆ını beyan etmişlerdir.

Finansal Destek: Yazarlar bu çalışmada finansal destek almadıklarını beyan etmişlerdir.

Yazar Katkıları: Yazarların tümü; makalenin tasarımına, yürütülmesine, analizine katıldığını ve son sürümünü onayladıklarını beyan etmişlerdir.

\section{KAYNAKLAR}

1. Who.int (homepage on the Internet) Global Atlas on Cardiovascular Disease Prevention and Control 2011 (cited June 2021). Available from: www.who.int.

2. Yavuz E, Girici M, Özden F ve ark. Namık Kemal Üniversitesi Tıp Fakültesi öğrenci ve çalışanlarında hipertansiyon farkındalığı. Namık Kemal Tip Derg 2017; 5: 118-4.

3. Mancia G, Fagard R, Narkiewicz K, et al. 2013 ESH/ESC Guidelines for the management of arterial hypertension: The task force for the management of arterial hypertension of the European Society of Hypertension (ESH) and of the European Society of Cardiology (ESC). J Hypertens 2014; 31: 1281-357.

4. Arıkan A, Aydın A, Ekerbiçer HÇ. Hipertansiyon tanısı olan hastaların hastalıkları hakkındaki bilgi düzeyleri ve ilişkili faktörler. Sakarya Tip Derg 2020; 10: 33-7.

5. Viera AJ, Cohen LW, Mitchell CM, SloanePD. High blood pressure knowledge among primary care patients with known hypertension: A North Carolina FamilyMedicineResearch Network (NC-FM-RN) Study. J Am Board Fam Med 2008; 21: 300-8.

6. He J, Muntner P, Chen J, et al. Factors Associated with hypertension control in the general population of the United States. Arch Intern Med 2002; 162: 1051-8.

7. Oskay EM, Önsüz MF. Topuzoğlu A. İzmir'de bir sağlık ocağı'nda başvuranların hipertansiyon hakkındaki bilgi, tutum ve görüşleri. ADÜ Tip Fakültesi Derg 2010; 11 : 3-9.
8. Arslantas EE, Sevinç N, Cetinkaya F, Günay O, Aykut M. Hipertansif kişilerin hipertansiyon konusundaki tutum ve davranışları. Ege Tip Derg 2019; 58: 319-21.

9. Aypak C, Önder Ö, Dicle M, Yıkılkan H, Tekin H, Görpelioğlu S. Hipertansif hastaların kan basıncı kontrol düzeylerinin ve tedavi uyumlarının değerlendirilmesi. Çukurova Üniversitesi Tıp Fakültesi Derg 2013; 38: 224-9.

10. Wee HL, Cheung YB, Li SC, Fong KY, Thumboo J. The impact of diabetes mellitus and other chronic medical conditions on health-related quality of life: is the whole greater than the sum of its parts? HQLO 2005; 3: 2.

11. Oliveria SA, Chen RS, McCarthy BD, et al. Hypertension knowledge, awareness, and attitudes in a hypertensive population. J Gen Intern Med 2005; 20: 21925.

12. Arıcı M, Birdane A, Güler K ve ark. Türk hipertansiyon uzlaşı raporu. Turk Kardiyol Dern Ars 2015; 43: 402-9.

13. Mancia G, Fagard R, Narkiewicz K, et al. The task force for the management of arterial hypertension of the European Society of Hypertension (ESH) and of the European Society of Cardiology (ESC). Eur Heart J 2013; 34: 2159-219.

14. Sacks FM, Svetkey LP, Vollmer WM, et al. Forthe DASH-Sodium Collaborative Research Group. Effects on bloodpressure of reduced dietary sodium and the Dietary Approaches to Stop Hypertension (DASH) diet. N Engl J Med 2001; 344: 3-10.

15. Vollmer WM, Sacks FM, Ard J, et al. Effects of diet and sodium intake on blood pressure. Ann Intern Med 2001; 135: 1019-28.

16. Chobanian AV, Hill M. National Heart, Lung, and Blood Institute Workshop on Sodiumand Blood Pressure: a critical review of current scientific evidence. Hypertension 2000; 35: 858-63.

17. Kelley GA, Kelley KS. Progressive resistance exercise and resting blood pressure: a meta-analysis of randomized controlled trials. Hypertension 2000; 35: 838-43.

18. Taylor-Tolbert NS, Dengel DR, Brown MD, et al. Ambulatory blood pressure after acute exercise in older men with essential hypertension. Am J Hypertens 2000; 13: 44-8.

19. Rossi A, Dikareva A, Bacon SL, Daskalopoulou SS. Theimpact of physical activity on mortality in patients with high blood pressure: a systematic review. J Hypertens 2012; 30: 1277-88.

20. Özer Z, Teke N, Turan GB. Bir üniversitede çalıșan personellerin hipertansiyon hakkındaki bilgi tutum ve görüşlerinin değerlendirilmesi. Sağlık Akademisyenleri Derg 2020; 2: 160-6.

21. Kronik Hastalık İzlemi Katılımcı Rehberi. Sağlık Bakanlığı, Halk Sağlığı Müdürlüğü, Kronik Hastalıklar Daire Başkanlığı, Birinci Basamak Sağlık Hizmeti, Ankara, 2017. https:// hsgm.saglik. gov.tr/tr/kronikhastaliklar-haberler/kronik-hastal\%C4\%B1klarizlemi-il-e\%C4\%9Fitimleri.html (Erişim Tarihi: Haziran 2021)

22. Eshah NF, Al-daken LI. Assessing publics' knowledge about hypertension in a community-Dwelling sample. J Cardiovasc Nurs 2016; 31: 158-7.

23. Teke N. Kirsal alanda yaşayan hipertansiyonlu bireylerin ilaç tedavisine uyum özellilik düzeyleri. Hemşirelik Ana Bilim Dalı. Yüksek lisans tezi. Konya: 2016 